\title{
O PROCESSO DE RECONSTRUÇÃO DO PROJETO POLÍTICO-PEDAGÓGICO EM UMA ESCOLA PÚBLICA ESTADUAL DE SANTA MARIA - RS
}

Jaqueline de Gaspari Ane Carine Meurer

\begin{abstract}
Resumo
Com esse artigo intencionamos sistematizar o estudo desenvolvido na pesquisa intitulada "Ensino Médio Público Estadual: a proposta da LDB e a efetivação do Projeto Político-Pedagógico das escolas da região central do município de Santa Maria”, que aconteceram no decorrer do ano de 2007. Objetivamos compreender o processo de reconstrução do PPP da escola pesquisada e acompanhar quais segmentos participavam ativamente desse movimento de reconstrução. Buscamos referências em uma abordagem qualitativa de enfoque etnometodológico. Vivenciamos discussões que problematizaram o PPP, intencionando repensar os espaços-tempo da escola, onde o novo Projeto Político-Pedagógico retratasse a realidade da mesma. Acompanhar o cotidiano escolar possibilitou-nos enfatizar que todos os segmentos precisam envolver-se, participando democraticamente do processo de reconstrução do PPP, que nunca cessa, e que mesmo enfrentando dificuldades, está sempre em constante renovação.
\end{abstract}

Palavras-chave: Projeto Político-Pedagógico, Reconstrução, Ensino Médio

\section{THE PROCESS OF RECONSTRUCTION OF THE POLITICAL-PEDAGOGIC PROJECT IN A STATE PUBLIC SCHOOL OF SANTA MARIA - RS}

\begin{abstract}
In this article we intend to systematize the study developed in the research entitled "State Public Senior High School: the LDB proposal and the PoliticalPedagogical Project effectivation of schools in the central city of Santa Maria”, which took place during the year 2007. We want to understand the reconstruction process of the PPP in the researched school and to see which segments have been active in this reconstruction movement. We seek a qualitative approach of the ethnomethodological focus. We live discussions that problematized the PPP, intending to rethink the space-time school, where the new Political-Pedagogical Project represented this reality. Monitor the school daily allowed us to emphasize that all parts need to engage and participate democratically in the PPP reconstruction process, which never finish, and that despite the difficulties, it is always under renovation.
\end{abstract}

Keywords:: Political-Pedagogical Project, Reconšstruction, Senior High School. 


\section{Introduzindo}

Através deste artigo pretendemos sistematizar o trabalho desenvolvido na pesquisa intitulada "Ensino Médio Público Estadual: a proposta da LDB e a efetivação do Projeto Político-Pedagógico das escolas da região central do município de Santa Maria”, que aconteceram no decorrer do ano de 2007.

Como pesquisadoras no campo da educação e como pedagogas necessitamos compreender as questões relacionadas à Educação Básica, abrangendo assim o Ensino Médio e seu funcionamento, bem como a elaboração do Projeto Político-Pedagógico. Dessa forma, a presente pesquisa visa suprir tal necessidade. Esse trabalho foi realizado em uma escola de Ensino Médio Público Estadual da região central do município de Santa Maria/RS. Após os primeiros contatos com a escola, e a disposição para o trabalho ser aceita, iniciou-se o acompanhamento da rotina escolar, mantendo uma maior interação com o segmento professores, especialmente, com o Serviço de Supervisão Escolar. A pesquisa ocorreu com visitas de freqüência semanal à referida escola de Ensino Médio, realizando-se também uma análise documental, que auxiliou no estudo.

\section{Métodos e metodologia}

Nossa pesquisa foi realizada de acordo com o acompanhamento da reconstrução do Projeto Político-Pedagógico da referida escola, para tanto, fizemos uso de um enfoque etnometodológico qualitativo, isto é, através da pesquisa empírica buscamos compreender os métodos utilizados pelos sujeitos em suas ações cotidianas, como esses sujeitos agem na prática e, principalmente, como se relacionam com os sujeitos que os rodeiam.

A etnometodologia refere-se a uma interpretação do mundo dos vários sujeitos escolares e foi com a inserção semanal das pesquisadoras, durante os meses pelos quais seguiu-se a pesquisa, que possibilitou, junto ao segmento professores, especialmente, o Serviço de Supervisão Escolar, observar a Instituição de Ensino Médio e, compreender um pouco desse mundo. Sendo assim, através do Serviço de Supervisão Escolar conseguimos acompanhar e vivenciar a ação de vários segmentos que faziam parte da escola, sendo entre eles os pais, os alunos, os professores e os funcionários. Observamos as suas tomadas de decisões, seus argumentos, sua linguagem, sua racionalidade. Imergindo no seu cotidiano, valorizamos o que eles tinham a dizer, compreendemos como criam e recriam a história da Escola. 
Esse acompanhamento da rotina e cotidiano escolar proporcionou também a oportunidade de fazer uma análise detalhada do antigo Projeto PolíticoPedagógico, do Regimento Escolar, do Plano Integrado da Escola, suas formas de elaboração, assim como, a Legislação atual que assegurava tais mudanças. Tais propósitos justificavam-se em função de atingirmos os objetivos a que nos propusemos. Para tanto, a pesquisa acontecia durante dois dias semanais, onde as pesquisadoras passavam a partilhar da rotina da escola.

Nosso entendimento sobre etnometodologia não se refere somente aos métodos usados na pesquisa, mas sim aos "métodos" que os sujeitos usam para realizar suas ações diárias, de forma que possam ser analisadas, buscando sua compreensão, a fim de entender seu meio histórico-social. Nas palavras de André (2000), nossos principais focos de interesse, ao optar pela etnometodologia são: os conhecimentos tácitos, as formas de entendimento do senso comum, as práticas cotidianas e as atividades rotineiras que forjam as condutas dos atores sociais.

\section{Fundamentando o Projeto Político-Pedagógico}

As mudanças que ocorreram a partir da Lei de Diretrizes e Bases $n^{0}$. 9.394/96 referentes ao Ensino Médio, as relações deste com o mundo do trabalho e suas atuais reconfigurações de sociedade, levaram-nos a pensar sobre qual é o Projeto Político-Pedagógico que uma escola precisa ter como referencial para suas atividades cotidianas.

O processo de criação ou atualização de um Projeto Político-Pedagógico significa repensar, refletir, buscar, inovar e incorporar novas idéias e formas democráticas de atuação à prática educativa, pensando em uma perspectiva transformadora de educação, o que exige compromisso de todos os profissionais de educação, sejam eles de escolas públicas ou particulares.

O maior desafio é sistematizar toda uma comunidade e toda sua história e realidade em um documento, que possa constituir a referência para a organização do trabalho pedagógico escolar. Desafio de expressar a intencionalidade político-pedagógica de um projeto de educação e de sociedade, articulado aos interesses e necessidades de uma sociedade escolar, ou seja, educação que assegure uma aprendizagem de qualidade para todos os envolvidos no processo.

Segundo Veiga (2001), um Projeto Político-Pedagógico emancipador é capaz de expressar sua intencionalidade pedagógica, cultural, profissional, além de um modelo de gestão democrático. O projeto não constitui-se apenas em um documento, mas na consolidação de um processo de ação-reflexão-ação 
que exige esforço conjunto e vontade política do coletivo escolar. Constitui-se em um processo onde a teoria e a prática se articulam em unicidade, sem primazia de uma sobre a outra, mas em interdependência, reciprocidade, dinamicidade.

Teoria e prática são elementos distintos, porém inseparáveis na construção do projeto. Nesse contexto, reforça-se a concepção de práxis, de prática refletida, de atividades teórico-práticas que têm, de um lado, a ação que subsidia o pensamento para a construção de novas idéias e formas diferenciadas de intervenções na realidade educacional, e, de outro, a teoria representada por um conjunto de idéias, sistematizado a partir da prática pedagógica. (VEIGA, 2001)

O Projeto Político-Pedagógico de escola exige reflexão acerca do papel social da escola na sociedade em que se encontra, para tanto é necessário investigação e reflexão. Nesse sentido é fundamental pensarmos em nosso país, Estado e município de tal forma que o projeto de escola articule-se a eles. Essa articulação sempre crítica deve ser objeto de investigação e reflexão o que consubstancia o projeto como espaço-tempo de aprendizagem de todos.

Uma prática pedagógica subentende uma dimensão política, assim torna-se necessário uma reflexão sobre práticas sociais e culturais. O currículo deve transformar o conteúdo em experiências, rompendo com as fronteiras tradicionais e, atravessando o sujeito em suas múltiplas dimensões. Sendo o Projeto Político-Pedagógico, o norteador de todas as ações exercidas na escola,

O projeto pedagógico é um documento que não se reduz à dimensão pedagógica, nem muito menos ao conjunto de projetos e planos isolados de cada professor em sua sala de aula. O projeto pedagógico é, portanto, um produto específico que reflete a realidade da escola, situada em um contexto mais amplo que a influência e que pode ser por ela influenciado. Em suma, é um instrumento clarificador da ação educativa da escola em sua totalidade. (VEIGA, 1998)

A clareza do Projeto Político-Pedagógico articulado, expresso, explícito por todos os segmentos que fazem parte da escola é que permitirá que o Ensino Médio delineie a sua especificidade dentro da Educação Básica brasileira.

\section{Reflexões e vivências na escola pesquisada}

Iniciamos a desenvolver nossa pesquisa. Atendendo inicialmente a soli- 
citação da supervisora escolar e também por fazer parte de nosso objetivo, de conhecer a escola, fizemos um levantamento da realidade escolar: número de alunos, número de professores, funcionários, equipe Diretiva, Orientação e Supervisão Escolar, suas proporções referentes à quantidade necessária de professores e equipe diretiva em relação ao número de alunos da escola, para um ensino de qualidade. Tudo isso é claro, com o acompanhamento da Supervisora e observação de todos aqueles que por sua sala precisassem passar ou solicitar algo, enfim, eram ricas as oportunidades de conhecer.

Ao fazermos a análise do Projeto Político-Pedagógico, Plano Integrado e Regimento Escolar, foi possível compreender a direção, ou seja, os objetivos que a escola estava seguindo até o momento, como se organizava na efetivação das suas ações, das tomadas de decisões e em relação às respectivas responsabilidades cabíveis a cada segmento escolar. Tomamos base no que alertou Domingos (1985), de que cada conteúdo deixa de ter significado por si só, para assumir uma importância relativa e passar a ter uma função bem determinada e explícita dentro do todo de que faz parte.

Dessa forma, estudando os documentos da escola, percebemos que seu foco de ensino é voltado à preparação para o ingresso no Ensino Superior, visa preparar o aluno para o que a atual sociedade exige, ou seja, qualificação. Sozinho, cada documento não tem sentido, mas unindo o que é relatado no Plano Integrado com o antigo Projeto Pedagógico, fica clara a função propedêutica que a escola havia assumido. A Supervisora queria escrever um Projeto Pedagógico que estivesse em consonância com a realidade que a escola estava vivendo no momento e não um projeto, em suas palavras, utópico, que ficaria trancado em uma gaveta depois de passar pelas instâncias superiores e que não alteraria em nada a rotina escolar.

O Projeto Político-Pedagógico tem a ver com a organização do trabalho pedagógico em dois níveis: como organização da escola como um todo e como organização da sala de aula, incluindo sua relação com o contexto social imediato, procurando preservar a visão de totalidade. Busca a organização do trabalho pedagógico da escola na sua globalidade. É essa a intenção da supervisora, com a qual trabalhamos, e que pretende escrever um Projeto que apenas formalize o que já está em andamento dentro da escola, sua organização cotidiana.

No decorrer de nosso trabalho de reconstrução do Projeto, era possível manter conversas com a Supervisora, a respeito dos inúmeros acontecimentos da rotina de supervisão. Entre troca de informações, quando questionada por que estava reescrevendo o Projeto Político-Pedagógico, "sözinha", a supervisora 
nos trouxe algumas coisas com o que pensar, sobre o futuro como professora, segundo ela:

\begin{abstract}
o professor quer vir para escola, dar a sua aula e ir embora, pois muitas vezes não trabalha somente em uma escola, tem outras atividades e, mesmo que não às tenha, não tem vontade de participar. A pressão, por parte do Estado, de enxugamentos de salários e de quadros de professores, faz com que os professores queiram ficar cada vez menos dentro da escola e, também a procurar outros incentivos financeiros (SUPERVISORA ESCOLAR).
\end{abstract}

A reformulação do antigo Projeto Político-Pedagógico de modo solitário por parte da Supervisora, contou com o auxilio das pesquisadoras em momentos como, por exemplo, a análise da documentação legal necessária à escrita do Projeto Pedagógico. Além disso, foram fornecidos textos e artigos que elucidassem melhor o processo de reconstrução do Projeto Político-Pedagógico que estava sendo desenvolvido.

Estamos falando de uma formação, inicial e continuada que exigia do professor para ser considerado "bom profissional" o desempenho de sua função em sala de aula, geralmente ligada à transmissão de conteúdos em sala de aula. Assim, essa nova concepção que exige do professor, além do saber da sua disciplina, o conhecimento dos saberes pedagógicos, a discussão e reflexão acerca do cotidiano da escola, da sua prática entre outras questões, exigem, também outra formação.

Com as observações e conversas informais, foi possível perceber que a intenção da escola é destacar a importância do Projeto Pedagógico como articulador das práticas existentes na escola, dos saberes norteadores dessa ação. Para esse projeto existir e se efetivar é necessário à organização coletiva dos docentes em torno desse mesmo projeto. Nesse ponto concentram-se as maiores dificuldades, pois a escola é dinâmica, seu corpo docente muda, seus alunos mudam, as relações com a comunidade também são reconstruídas.

Ao vivenciarmos a rotina da sala de supervisão, pudemos participar de momentos em que a supervisora escolar atendia solicitações de alunos, conversava com pais que vinham até a escola e, atendia também os demais professores a respeito de suas atividades educacionais; tal rotina prolongava-se por quase todo o dia, enfim, como nos disse a própria supervisora:

\footnotetext{
[...] é difícil reconstruir um Projeto Político-Pedagógico e, fica mais complicado ainda sem a participação dos demais segmentos, sendo que preciso desviar minha atenção deste trabalho a todo o momento, atendendo a rotina da Supervisão. (SUPERVISORA ESCOLAR)
} 
A escola tinha em seu quadro de profissionais, cento e quarenta e sete professores e trinta e um funcionários, possuindo um total de mil e oitocentos alunos, distribuídos em sessenta e uma turmas, nos três turnos da escola, sendo que pela manhã estudam segundos e terceiros anos, à tarde somente o primeiro e à noite os três anos têm aula. São três Supervisoras, sendo que apenas uma delas trabalha com carga horária de quarenta horas. Segundo a supervisora com a qual manteve-se contato, sem auxílio não seria possível reformular o Projeto, devido a falta de tempo, em função da demanda que a rotina escolar exigia.

Muitos podem ser os motivos e dificuldades em se concretizar um Projeto Pedagógico de escola e, a falta de interesse e participação pode ser um deles, contudo, o primeiro passo foi dado: a escola estava buscando a renovação. No entanto, esse é um processo lento e precisa de apoio, para tanto a escola precisa sempre estar aberta ao diálogo, disponível em receber estagiários, pesquisadores de iniciação científica e demais trabalhos de pesquisa, que possam contribuir com a formação de seus alunos.

Foi possível perceber um grande envolvimento de alunos, professores e comunidade escolar nos debates que antecederam as eleições para Grêmio Estudantil e Conselho Escolar. No entanto, necessitaríamos de um maior envolvimento nos vários espaços-tempo escolares para compreender se, de fato, essa participação se efetiva no cotidiano da escola ou ocorre somente em momentos específicos como em eleições tanto para Grêmio Estudantil quanto para Conselho Escolar, ou seja, embora estivéssemos dentro da escola, duas vezes durante a semana, nosso envolvimento ainda foi pequeno em relação a todos os segmentos escolares, suas funções e tarefas. Acompanhamos a eleição do Grêmio Estudantil, onde houve participação dos alunos, questionamentos e sugestões de melhoria da instituição, mas, se não tivesse havido eleição, não poderíamos saber, neste curto espaço de tempo se os alunos são realmente participativos. Consideramos importante a participação do Grêmio Estudantil em todas as atividades desenvolvidas pela escola, que tomem conhecimento do funcionamento da escola, como são efetivadas suas decisões, quais são os direitos e deveres dos alunos, professores e demais segmentos da comunidade escolar, a fim de que possam fazer uma gestão participativa, que atenda as necessidades de todos.

Reafirmando as palavras de Ribeiro (2002), o conhecimento é uma construção social de conflitos e interesses antagônicos. A própria formulação e a articulação de um Projeto Político-Pedagógico dependem e levam em conside- 
ração decisões coletivas acerca de compreensões diversas da educação, do corpo docente, discente, funcionários da escola. Enfim, toda a comunidade deveria envolver-se na realização deste Projeto de escola, porém, com nossa observação percebemos que não é bem assim, ainda há pouca participação de todos os segmentos escolares.

Com o intuito de suprir os objetivos que havíamos estabelecido o trabalho com a Supervisora foi substituído, em algumas ocasiões, por observações em sala de aula, com o propósito de ter um acompanhamento objetivo do cotidiano escolar, perceber a relação professor - aluno - equipe diretiva. Observamos se havia o questionamento dos alunos sobre o que é o Projeto Político-Pedagógico, se tinham conhecimento de que este estava sendo reformulado, se sabiam que como discente tinham o direito de opinar e participar da referida reformulação.

Nas aulas observadas, em nenhum momento foi feita qualquer referência ao Projeto Pedagógico da escola. As aulas mostraram-se dinâmicas, objetivas, com um bom desenvolvimento de conteúdo, os professores estavam abertos a ouvir as falas e intervenções dos alunos, desde que com relação ao assunto da aula. Vale observar que os professores estavam sempre dando dicas interessantes sobre o que poderia ou não ser cobrado em vestibulares, ENEM (Exame Nacional do Ensino Médio) e PEIES (Programa de Ingresso ao Ensino Superior da UFSM), com sugestões de livros, leituras de jornais e revistas com reportagens de auxílio aos vestibulandos, enfim, o que de certa forma, está de acordo com o que a supervisora tem em mente para o Projeto Político-Pedagógico: uma escola que assume ser propedêutica e que cumpre da melhor forma possível sua meta.

Uma escola de Ensino Médio tem como finalidade primordial proporcionar a consolidação e o aprofundamento dos conhecimentos adquiridos no Ensino Fundamental, possibilitando o prosseguimento de estudos, como também a preparação básica para o trabalho e a cidadania do educando. Nessa perspectiva, além de preparar para a continuidade dos estudos e uma futura atuação profissional, ou qualificação técnica, a escola pesquisada visava preparar para o enfrentamento das dificuldades colocadas pela experiência da vida em sociedade.

Havia também reuniões pedagógicas na escola, bem como conselhos de classe. Uma vez por semana, parte do horário letivo era destinado às reuniões pedagógicas, sendo que quando essas não ocorriam esse tempo livre era destinado à recuperação de dias letivos perdidos ou para os professores realizarem seus planejamentos. 
Quanto ao Conselho de Classe, obtivemos informações que parecem igualar-se aos conceitos de senso comum do que seja o Conselho de Classe. Esse referia-se a exposição pública e discussão de notas a cada fim de trimestre, mas somente com a participação dos professores, da supervisão, da orientação e da direção, sem a participação dos alunos. Só havia conselho de classe participativo quando os líderes de turma ou professores pediam a realização do mesmo à Supervisão; isso ocorria quando havia alguma briga, conversas em demasia na turma ou qualquer outro problema com a aula ou com algum professor.

A escola pesquisada era grande e com muitas atividades, contudo, sempre esteve aberta para o diálogo e a troca de experiências em busca do conhecimento. Esse diálogo escola-universidade proporcionou o envolvimento de duas comunidades em efetivar objetivos comuns. O principal deles refere-se à formação docente e profissional, nesse sentido entendemos que se qualifica o projeto de escola, e efetiva-se a abertura para o novo.

\section{Concluindo}

Ao longo de toda a pesquisa observamos as dificuldades de adaptação que as Escolas Públicas enfrentam às novas realidades impostas pela sociedade, tentando realizar um trabalho que esteja voltado para formação integral de seu aluno. Através do trabalho que realizava, a escola pesquisada tinha como meta preparar o educando para dar continuidade aos seus estudos, estando ciente das transformações da sociedade, sabendo que o conhecimento é presença garantida em qualquer exigência futura. Embora estivesse alicerçado em um ensino tradicional, o trabalho pedagógico realizado na escola voltava-se para o social, o desenvolvimento coletivo, mas que pensava também no avanço individual, permitindo ao aluno construir seu próprio conhecimento.

Acreditamos ser inegável e de extrema relevância que a comunidade escolar participe de reuniões no qual o assunto em pauta seja o processo de reconstrução do Projeto Político-Pedagógico, para que cada vez mais, esse documento passe da simples escrita a uma reflexão sistematizada e coletiva de todos os segmentos. Com a participação de todos esse documento não ficará guardado em uma gaveta após ser aprovado e tornar-se-á de fato, um importante parâmetro na ação cotidiana da escola. Na escola pesquisada, o processo de participação já começou e, cabe a equipe diretiva continuar estimulando e valorizando a participação de todos. 
Ao término de nossa pesquisa, a equipe de supervisão da escola pesquisada havia tomado consciência de que o Projeto Político-Pedagógico não era um documento acabado e que precisa ser atualizado. Que este estaria em constante movimento e seria sempre reformulado, com a ajuda de todos os segmentos, buscando melhorar o trabalho realizado em prol de uma formação de qualidade a seus alunos. Entendemos que o PPP torna-se significativo quando reflete os anseios e necessidades de sua comunidade escolar, contudo, é preciso avaliar periodicamente o Projeto Político-Pedagógico, reescrevê-lo, para que todos na instituição possam ser melhor atendidos em seus anseios e usufruir de uma educação de qualidade.

O documento que foi reformulado, durante o período de pesquisa na escola, não foi escrito "coletivamente", ou seja, não contou com a participação de sua comunidade escolar. O interesse e participação dos segmentos escolares na reconstrução do Projeto Político-Pedagógico foram totalmente limitados. Sendo a intenção de tal reformulação atualizá-lo à realidade da Escola, nos foi possível perceber que o novo Projeto Político-Pedagógico dava ênfase a preparação dos alunos para as variadas formas de ingresso tradicionais ao Ensino Superior e, que este atendia à sua demanda.

Existem várias limitações no processo de construção - reconstrução de um Projeto Político-Pedagógico em Escola, seja ela de Ensino Médio ou não, embora, esperamos estar contribuindo com nossa reflexão ao passo que essa temática possa estar presente em cursos de formação inicial e continuada para professores, supervisores e diretores.

Um Projeto Político-Pedagógico de escola necessita de muitas discussões, trocas de idéias e de vivências, que seja subsidiado pelo cotidiano da comunidade escolar como um todo, firmado sobre a realidade da escola que está efetivando. Acreditamos em ações como essas, que com certeza fortalecem a escola e permitem uma evolução da qualidade na educação, o que sem dúvida renderá aspectos positivos tanto para os alunos quanto para a escola e sua comunidade.

\section{Referências bibliográficas}

ANDRÉ, Marli Elisa D. Afonso de. Etnografia da prática escolar. $4^{\mathrm{a}}$ Ed. Campinas, São Paulo: Papirus, 2000 - Coleção Prática pedagógica.

BRASIL. Lei N. 9.394, de 20 de dezembro de 1996. Dispõe sobre as Diretrizes e Bases da Educação Nacional e dá outras providências. Brasília, 1996. Disponível em: http://www.mec.gov.br/legis/zip/lei9394.zip Acesso em: jul. 
2003.

DOMINGOS, Ana Maria; et al. A teoria da Bernstein em sociologia da educação. Lisboa, Fundação Calouste Gulbekian, 1985.

RIBEIRO, Marlene. Ensino Médio e Educação Profissional Sob Relações de Hegemonia: Terreno Perdido ou Construção de Novas Relações? Revista Educação, Santa Maria, vol. 27, $\mathrm{n}^{\circ}$ 1, 2002.

VEIGA, Ilma Passos de Alencastro. As dimensões do Projeto PolíticoPedagógico. Campinas, Papirus, 2001. $\overrightarrow{1998}$.

Escola: espaço do Projeto Político-Pedagógico. Campinas, Papirus,

\section{Jaqueline de Gaspari}

Graduanda em Pedagogia - UFSM

E-mail para correspondência:

jaqueline.degaspari@gmail.com

\section{Ane Carine Meurer}

Doutora em Educação. Professora do Departamento de Fundamentos da Educação do Centro de Educação da UFSM.

E-mail para correspondência:

acmeurer@terra.com.br 